๑ Entomologica Fennica. 29 December 2003

\title{
First instar larvae of nine West-Palaearctic species of Pollenia Robineau-Desvoidy, 1830 (Diptera: Calliphoridae)
}

\author{
Krzysztof Szpila
}

Szpila, K. 2003: First instar larvae of nine West-Palaearctic species of Pollenia Robineau-Desvoidy, 1830 (Diptera: Calliphoridae). — Entomol. Fennica 14: 193-210.

The present paper describes first instar larvae of Pollenia amentaria (Scopoli), Pollenia angustigena Wainwright, Pollenia atramentaria (Meigen), Pollenia labialis Robineau-Desvoidy, Pollenia mayeri Jacentkovský, Pollenia pediculata Macquart, Pollenia rudis (Fabricius), Pollenia similis (Jacentkovský), and Pollenia vagabunda (Meigen). Morphologies of the first instar larvae of the above-mentioned species are studied with respect to their potential use for species identification. A key for the identification of all first instar larvae of Pollenia known at present is provided.

Krzysztof Szpila, Nicolas Copernicus University, Institute of Ecology and Environmental Protection, Department of Animal Ecology, Gagarina 9, 87100 Toruń,Poland; E-mail: szpila@biol.uni.torun.pl

Received 12 February 2003, accepted 24 April 2003

\section{Introduction}

The aim of this paper is to revise the first-instar larval morphology of the most common central European Pollenia species and to provide a key for their identification. This information enables the verification of earlier works on the genus, and it will be important for reassessing the recent views on phylogeny and classification of the genus.

The genus Pollenia Robineau-Desvoidy, 1830 is represented by more than 100 species in the Palaearctic, Nearctic, Oriental and Australasian Regions. The Palaearctic fauna includes 42 known species, with the Western Palaearctic being much more species rich than the Eastern Palaearctic (Rognes 1988, 1998).

The imagines of many cluster-fly species are very abundant and at least in the Western Palaearctic dominate in blowfly communities. However, data on the bionomics of their pre- imaginal stages are very scarce. Apart from some descriptions of the preimaginal stages of Pollenia pediculata Macquart, 1834 (see below), larval morphology has been known for only one species, Pollenia dasypoda Portschinsky, 1881 (Tawfik \& El-Husseini 1971).

The larvae of all Pollenia species for which the biology is known are earthworm parasitoids or predators (third instar larvae may leave the body of their moribund host and feed on it externally). This association was first recognized by Charles Darwin (Hall 1948). Keilin (1909, 1915), Webb and Hutchinson (1916), DeCoursey (1927, 1932) in Europe, and Pimentel and Epstein (1960) in North America gave preliminary information about parasitism of earthworms by Pollenia. More detailed descriptions of larval stages, biology and morphology are presented by Yahnke and George (1972), Thomson and Davies (1973a, 1973b, 1974), and Richards and Morrison (1973). 
Zrazhevskiy (1957), Krivosheina (1961) and Victorov-Nabokov and Verves (1975) found earthworms being attacked by Pollenia species in Russia and the Ukraine. All of these works identify their target species as Pollenia rudis (Fabricius, 1794), yet they all appeared before the thorough systematic revision of the genus by Rognes (1987, 1988, 1991a, 1991b, 1991c, 1992). Both American and European reports differ in their descriptions of the duration of preimaginal stages and host ranges, and it is likely that several species are involved. Rognes (1987) divided the Pollenia rudis species group into seven distinct species based on imaginal features: $P$. angustigena, $P$. hungarica, $P$. paupera (as $P$. longitheca, cf. Rognes 1991c), P. luteovillosa, $P$. pediculata, $P$. rudis and Pollenia sp. He included them in the newly formed rudis species-group. We still do not know whether the reported differences in biology stem from differences in systematic position. Some information on the biology of cluster flies is contained in Séguy (1941) and Ibrahim (1984), yet these authors did not provide any description of the preimaginal stages.

The most deviating data on larval morphology were given by Keilin (1915). Yahnke and
George (1972) discussed Keilin's descriptions in detail and concluded that the larvae did not belong to $P$. rudis. Rognes (1991a, 1998) suggested that Keilin described a species belonging to the viatica species-group. Unfortunately, preimaginal stages are not known for any of the species of that group, and formal verification of Rognes' suggestion is needed.

\section{Material and methods}

\subsection{Obtaining of first instar larvae}

Females of various Pollenia species were caught at the following sites in Poland: Nicolas Copernicus University Research Centre of Applied Biology in Koniczynka near Toruń (UTM: CD48), edge of the airport of the Pomerania Aeroclub in Toruń (UTM: CD37), area near Zbocza Płutowskie reserve (UTM: CE20), Unisław (UTM: CD29), Piwnicki forest (UTM: CD38), Czarny Bryńsk (UTM: DD19), Fiałki (UTM: DD19), Grudziądz (UTM: CE42), Milechowy reserve (UTM: DB53), and the Pieprzowe Mountains near Sandomierz (UTM: EB51).

To obtain larvae, each female was kept separately in a $150 \mathrm{ml}$ glass jar with a layer of filter paper on the bottom and a finely perforated cover. Every two days the filter paper and the jar walls were sprinkled with a small amount of

Table 1. Eggs and first instar larvae of Pollenia Robineau-Desvoidy obtained. * = season 2002, others season 2001.

\begin{tabular}{|c|c|c|c|c|}
\hline ID & Species & Life duration in experiment & Number of eggs & Number of larvae \\
\hline 1 & P. amentaria & 12 July-27August & 5 & 5 \\
\hline 182 & $P$. amentaria & 12 July-5 August & 32 & 12 \\
\hline 34 & $P$. angustigena & 9 May-22 May & 72 & 15 \\
\hline 33 & $P$. angustigena & 9 May-27 May & 124 & 78 \\
\hline 45 & $P$. atramentaria & 9 July-12 July & 65 & 16 \\
\hline 69 & P. labialis & 6 July-22 July & 125 & 85 \\
\hline 92 & P. mayeri & 11 August-16 August & 22 & 4 \\
\hline 104 & P. mayeri & 19 July-6 August & 20 & 9 \\
\hline 187 & P. mayeri & 24 June-28 June* & 16 & 11 \\
\hline 110 & P. pediculata & 5 July-15 July & 85 & 60 \\
\hline 183 & P. pediculata & 5 July-11 July & 17 & 14 \\
\hline 122 & $P$. rudis & 8 May-18 May & 32 & 28 \\
\hline 139 & P. rudis & 21 June-28 July & 58 & 17 \\
\hline 136 & P. rudis & 6 June-12 July & 57 & 43 \\
\hline 135 & $P$. rudis & 6 June-21 June & 68 & 40 \\
\hline 160 & P. similis & 29 April-5 June & 74 & 42 \\
\hline 158 & P. similis & 13 August-21 August & 26 & 23 \\
\hline 184 & P. similis & 1 May-7 May & 9 & 7 \\
\hline 185 & $P$. similis & 3 May-8 May & 10 & 10 \\
\hline 178 & P. vagabunda & 30 April-15 May & 73 & 58 \\
\hline 186 & P. vagabunda & 18 April-13 June* & 18 & 8 \\
\hline
\end{tabular}


distilled water $(0.2-0.3 \mathrm{ml})$. As described by Yahnke and George (1972) granulated sugar was used to feed the adult flies. The sugar was added in solid form every $2-3$ days in small amounts (5-10 granules). Rearing was done at room temperature $\left(\mathrm{ca} .18^{\circ} \mathrm{C}\right.$ ) and high relative humidity (ca. $70 \%$ ). In total, 187 females of 11 species were kept, and 58 of them ( 9 species) laid eggs. Larvae hatched in 21 cases (Table 1). After oviposition some of the eggs were immersed in $70 \%$ alcohol. The remaining eggs were kept in Eppendorf test-tubes until they hatched. Larvae were killed by soaking in hot water (to avoid deformation) and stored in 70\% alcohol.

\subsection{Preparation}

Larvae were mounted in Canada balsam and Hoyer's medium. Note that Fig. 15c shows the ventral view of the cephalopharyngeal skeleton in its natural shape, while the basal sclerites shown in other illustrations were slightly moved sideways and tilted to some extent when flattened by the cover slip.

Illustrations were produced from photographs made with the use of a RGB BASLER A 113C digital camera combined with a NIKON SMZ800 stereomicroscope. SEM pictures were taken with the use of a Jeol Scanning Microscope JSM6300. Larvae were dehydrated through $80 \%, 90 \%$ and $99.5 \%$ ethanol, critical point dried in $\mathrm{CO}_{2}$ and coated with gold.

The terminology used here differs from that of Yahnke and George (1972) but follows Rognes (1991b) and Courtney et al. (1998) (Table 2).

\section{Results}

First instar larvae of Pollenia are typical for the Calyptratae in having a distinct pseudocephalon, three thoracic (termed T I-T III below) and eight abdominal segments (A I-A VIII). Each of the two pseudocephalic lobes has an antenna and a maxillary palpus with several sensillae (Fig. 3a). The oral ridges are absent.

The cephalo-pharyngeal skeleton is clearly visible through the cuticle. It is composed of a basal sclerite, intermediate sclerite, labrum, and mouthhooks (Figs. 1b-c). The frontally positioned labrum is clearly separated from the parastomal bars and highly sclerotized, tapering gradually from the base towards the pointed anterior end. Some species have a slightly ventrally curved labrum, in others it is straight or even dorsally curved. The labrum is basally divided into right and left arms that are separated by a sagittal cleft of more or less well-defined width. The arms unite anteriorly creating one functional whole. The parastomal bar (in form of two highly sclerotized parallel arms) forks at the posterior end into the ventral cornua and the vertical plate. The vertical plate is connected with the dorsal cornua. The ventral cornua are united with a membrane, which constitutes the floor of the pharynx. Ventral cornua, dorsal cornua and vertical plates are more or less sclerotised. Anteriorly, the dorsal cornua have projections curving inwards. None of the species, however, has the projections united medially to form the dorsal bridge that is present in most other blowfly larvae. The mouthhooks are elongated plates situated below the labrum. Width and degree of sclerotization differ in each species. Near the oral opening, the distal part of the mouthhooks form projections covered with spinules that point forward. The intermediate sclerite is located between the arms of the parastomal bar (Fig. 1c). It has two anterior projections and is connected laterally with the parastomal bar and posteriorly with the salivary ducts.

The anterior part of the ventral surface of $\mathrm{T} \mathrm{I}$ has numerous spines. In most species they are positioned in 3-7 rows over the ventro-lateral parts of the segment, just behind the oral opening. Keilin's organ, with three oblong bristles, are situated on the ventro-lateral surface of each thoracic segment (Fig. 3c). The lateral surface of each tho-

Table 2. Terminology of structures of the cephalopharyngeal skeleton of the first instar Pollenia larva used in the present work in comparison with the terminology used by Yahnke and George (1972).

\begin{tabular}{ll}
\hline Yahnke \& George (1972) & Present paper \\
\hline Oral hook & Labrum \\
Dental sclerite & Mouthhook \\
Hypostomal sclerite & Parastomal bar \\
Infrahypostomal sclerite & Intermediate sclerite \\
Salivary duct & Salivary duct \\
Dorsal cornua & Dorsal cornua \\
Ventral cornua & Ventral cornua \\
\hline
\end{tabular}



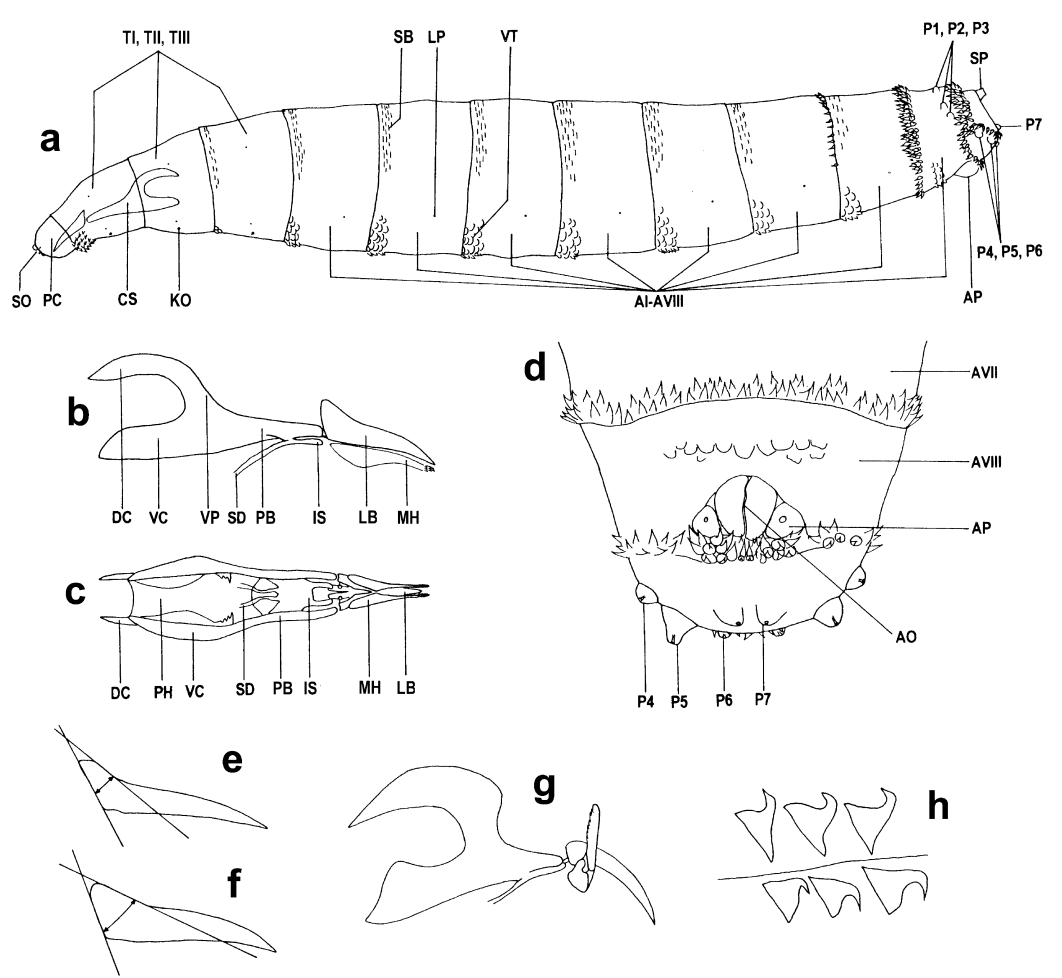

Fig. 1. Morphology of the first instar larva of Pollenia sp. - a. Whole body. - b. Cephalopharyngeal skeleton (lateral view). - c. Cephalopharyngeal skeleton (ventral view). - d. Posterior body end (ventral view). $-\mathrm{e}$. Labrum of $P$. angustigena. $-\mathrm{f}$. Labrum of $P$. pediculata. $-\mathrm{g}$. Cephalopharyngeal skeleton of undetermined Pollenia larva (redrawn from Keilin, 1915: fig. 36). - h. Spines on the anterior and posterior edges of the abdominal segments of the undetermined Pollenia larva (redrawn from Keilin, 1915: fig. VI). Abbreviations: AlAVIII - abdominal segments, AO - anal opening, AP - anal papilla, CS - cephalopharyngeal skeleton, KO - Keilin's organ, DC - dorsal cornua, IS - intermediate sclerite, LB - labrum, LP - lateral papillae, MH mouthhook, P1 - dorsal papillae, P2 - subdorsal papillae, P3 - supralateral papillae, P4 - infralateral papillae, P5 - subventral papillae, P6 - ventral papillae, P7 - supraventral papillae, PB - parastomal bar, PC - pseudocephalon, PH - pharynx, SB - band of spinules rows, SD - salivary duct, SO - sensory organs, SP - spiracles, TI-TIII - thoracic segments, VC - ventral cornua, VP - vertical plate, VT - ventral tubercles.

racic segment has an additional pair of lateral papillae (LP). The first seven abdominal segments have $3-5$ rows of posteriorly directed ventral tubercles (VT) on the anterior part of the ventrolateral surface (Fig. 1a). On the dorsal and partly on the lateral surfaces there are several separate rows of clustered blunt-tipped spinules $(P$. amentaria, $P$. angustigena, $P$. pediculata, $P$. rudis, $P$. similis), irregular rows of clustered sharp-tipped spinules ( $P$. atramentaria), single irregular band of larger spines only on T III, A I and A II ( $P$. mayeri), single discontinuous band of blunt-tipped spinules $(P$. vagabunda) or in case of one species $(P$. labialis) there are no spinules or spines. These spinules are also present (but to a to a varying degree) on the segments T II and T III. Along the posterior edge of the A VII are rows of large spines pointing anteriorly. The number of spines varies from $0-5$ depending on the position (dorsal, lateral, or ventral) and on the species. In most species a single row of weaker, lobe-like spines is also present dorsally and laterally along the posterior edge of A VI. Segment A VIII has a wide spinose band (1-3 rows) with spines pointing anteriorly. In a few species the size and the number of spines on the ventrolateral and ventral surfaces are reduced. From the transverse spinal band on the lateral surface of A VIII subsequent more or 


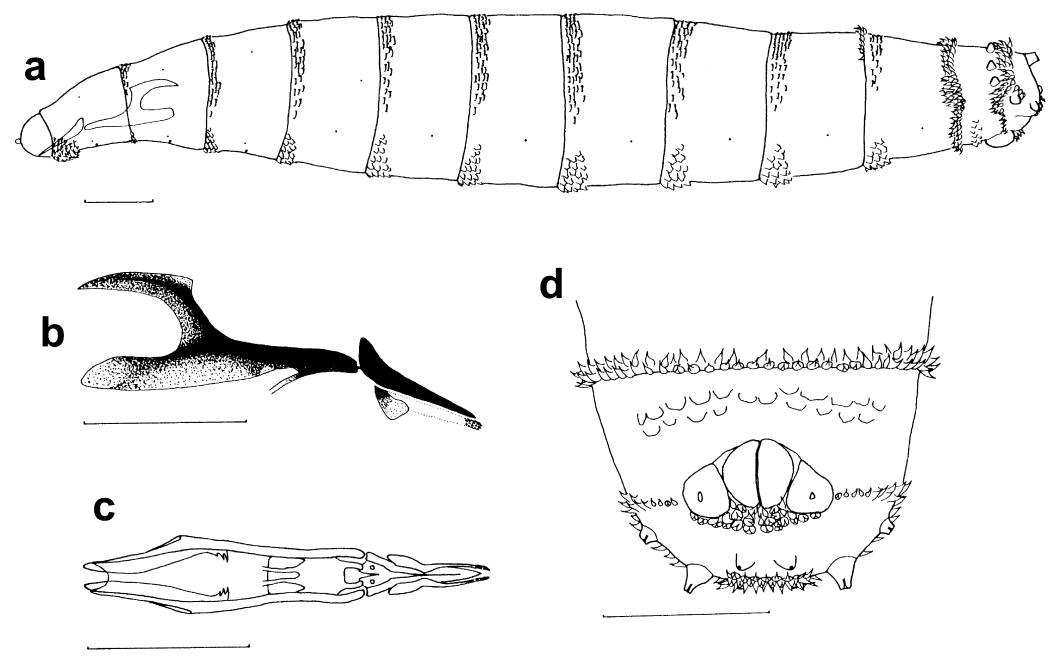

Fig. 2. First instar larva of Pollenia amentaria (Scopoli, 1763). - a. Whole body. - b. Cephalopharyngeal skeleton (lateral view). c. Cephalopharyngeal skeleton (ventral view). d. Posterior body end (ventral view). Scale $0.1 \mathrm{~mm}$.

less horizontal spinose bands radiate. Depending on the species they may terminate near the subventral papilla (P5) or unite on the posterior surface of the last segment. The posterior spiracles on segment A VIII are situated on small protuberances just behind the dorsal part of the transverse spinose band. The anal opening is situated on the ventral part of segment A VIII and is surrounded by two large anal papillae (Fig. 1d). The anus forms a crevice situated along the longitudinal axis of the body and is surrounded by two semi-circular protrusions. The ventral part of the transverse spinose band is located just behind the anal opening and its surrounding papillae. The remaining papillae on the final segment are situated as follows: the dorsal (P1), subdorsal (P2), and supralateral papillae (P3) are placed in front of the transverse spinose band, whereas the supraventral papillae (P7) are located above, and the infralateral (P4), subventral (P5) and ventral (P6) papillae below the horizontal spinose bands. The tip of each papilla is concave and equipped with funnel-like tubes.

3.1. Pollenia amentaria (Scopoli, 1763) (Figs. 2a-d, 3a-f)

Average body length $1.51 \mathrm{~mm}(\mathrm{SD}=0.03)$, average width $0.2 \mathrm{~mm}(\mathrm{SD}=0.01)$. Oval, elongated antenna. Labrum straight, narrow, and strongly elongated. Mouthhooks of similar shape, strongly sclerotised only in the basal part. Vertical plate of average length, relatively narrow, with its width almost equal to the width of dorsal cornua. Ventral tubercles present on segments T II and T III and on all the abdominal segments. They form relatively wide plates. Anteriorly, the dorsal surface of the segments has several separate rows of clustered blunt-tipped spinules. Spines present dorsally along posterior edge of A VI. Two clear rows of strong spines ventrally along posterior edge of A VII. The ventral tubercles on A VIII arranged in 2 rows, whereas in the central part only a single row is present. Anal opening oval and nearly round.

\subsection{Pollenia angustigena Wainwright, 1940} (Figs. 4a-d)

Average body length $1.55 \mathrm{~mm}(\mathrm{SD}=0.03)$, average width $0.22 \mathrm{~mm}(\mathrm{SD}=0.01)$. Slightly flattened antenna. Labrum narrow, strongly elongated, and slightly curved downwards. The mouthhooks are of a similar shape - long, very narrow, slightly turned downwards, strongly sclerotised only in the basal part. Vertical plate of average length, relatively narrow, as wide as dorsal cornua Ventral tubercles present on T III (sometimes also on T II) and on all the abdominal segments, forming wide plates (as in $P$. pediculata, Fig. 13e). Anteriorly, the dorsal surface of the segments has several separate rows of clustered blunt-tipped spinules. Spines are present dorsally along posterior edge of A VI. One row of spines ventrally along the posterior edge 


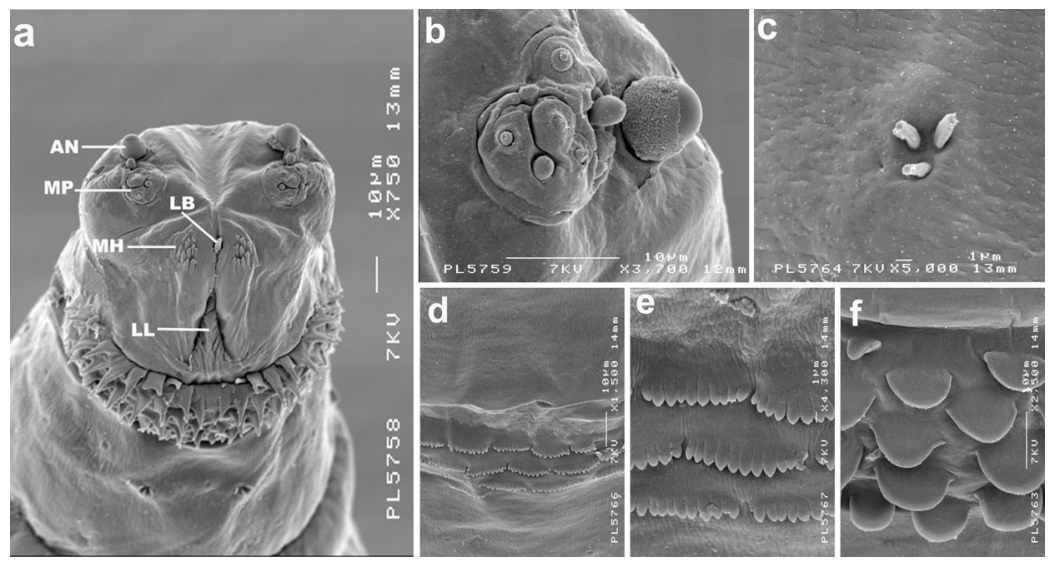

Fig. 3. First instar larva of Pollenia amentaria (Scopoli, 1763). - a. Anterior body end (ventral view). - b. Sensory organs on pseudocephalon. - c. Keilin's organ. $-d$. Spinulation on anterior dorsal surface of the abdominal segments (A II). - e. Same. - f. Ventral tubercles (A II). Abbreviations: AN - antenna, LB labrum, LL - labial lobe, MH - mouthhook, MP - maxillary palpus.
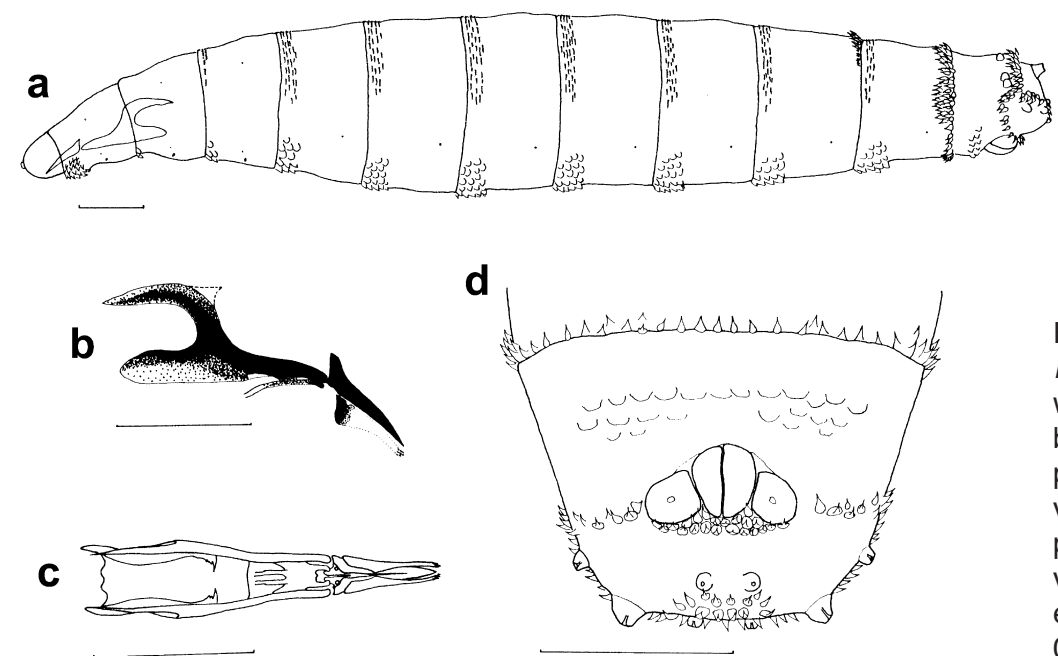

Fig. 4. First instar larva of Pollenia angustigena Wainwright, 1840. - a. Whole body. - b. Cephalopharyngeal skeleton (lateral view). - c. Cephalopharyngeal skeleton (ventral view). - d. Posterior body end (ventral view). Scale $0.1 \mathrm{~mm}$.

of A VII. Ventral tubercles on A VIII in 2-3 rows, whereas in the central part only one row present. Anal opening oval, slightly elongated towards the length axis of the body.

\subsection{Pollenia atramentaria (Meigen, 1826) (Figs. 5a-d, 6a-e)}

Average body length $1.69 \mathrm{~mm}(\mathrm{SD}=0.04)$, average width $0.22 \mathrm{~mm}(\mathrm{SD}=0.01)$. Considerably elongated antennae. Labrum slightly turned upwards. Mouthhooks simple and slightly sclerotised at the basis. Vertical plate long and clearly perpendicular to the dorsal and ventral cornua. Its narrowest part is thinner than the dorsal cornua at its widest. Ventral tubercles present on T II and TIII and on all abdominal segments, forming relatively elongated plates. Anteriorly, the dorsal surface of the segments has irregular rows of clustered sharp-tipped spinules. On T III and A I the ventral tubercles 
Fig. 5. First instar larva of Pollenia atramentaria (Meigen, 1826). - a. Whole body. - b. Cephalopharyngeal skeleton (lateral view). c. Cephalopharyngeal skeleton (ventral view). d. Posterior body end (ventral view). Scale $0.1 \mathrm{~mm}$.

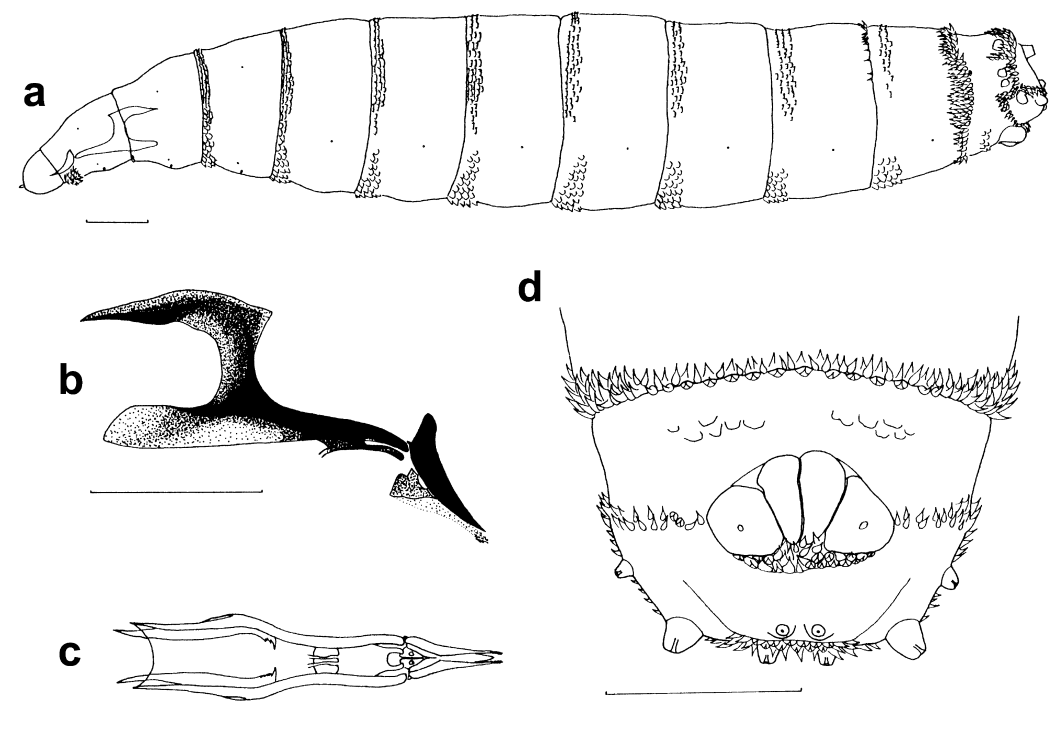

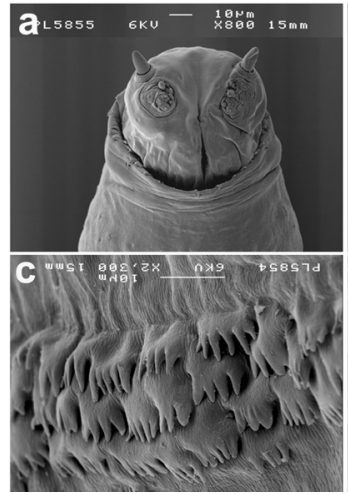
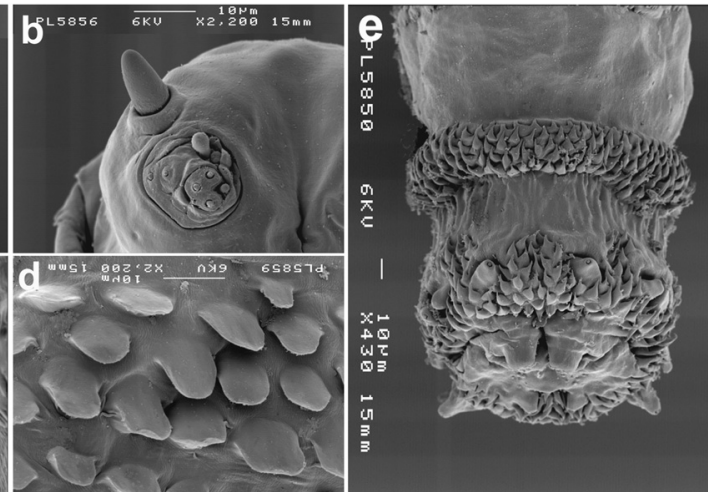

Figs 6. First instar larva of Pollenia atramentaria (Meigen, 1826). - a. Anterior body end (ventral view). - b. Sensory organs on pseudocephalon. - c. Spinulation on anterior dorsal surface of the abdominal segments (A II). - d. Ventral tubercles (A II). - e. Posterior body end (dorsal view).

and dorsal spine rows unite laterally, forming a band that encircles the whole segment. Spines present dorsally along posterior edge of A VI. Strong spines in high concentration forming two clear rows ventrally along posterior edge of $\mathrm{A}$ VII. Ventral tubercles on A VIII in 1-2 rows, absent from the midventral part. Anus oblong, slightly heart-shaped. A wide stripe of spines (45 rows) is present between the dorsal papillae (P1), with similar but thinner stripes (2-3 rows) between the dorsal (P1) and the subdorsal (P2) papillae.

\subsection{Pollenia labialis Robineau-Desvoidy, 1863} (Figs. 7a-d, 8a-d)

Average body length $1.58(\mathrm{SD}=0.03) \mathrm{mm}$, average width $0.24 \mathrm{~mm}(\mathrm{SD}=0.01)$. Antennae short and nearly spherical. Labrum straight and relatively short. Mouthhooks straight, widened at the basal and distal part, highly sclerotised in the distal part, slightly less in the proximal part, (the middle part poorly sclerotised). Vertical plate relatively short and wide, clearly wider than the dorsal cornua. Numerous long, narrow and slightly 

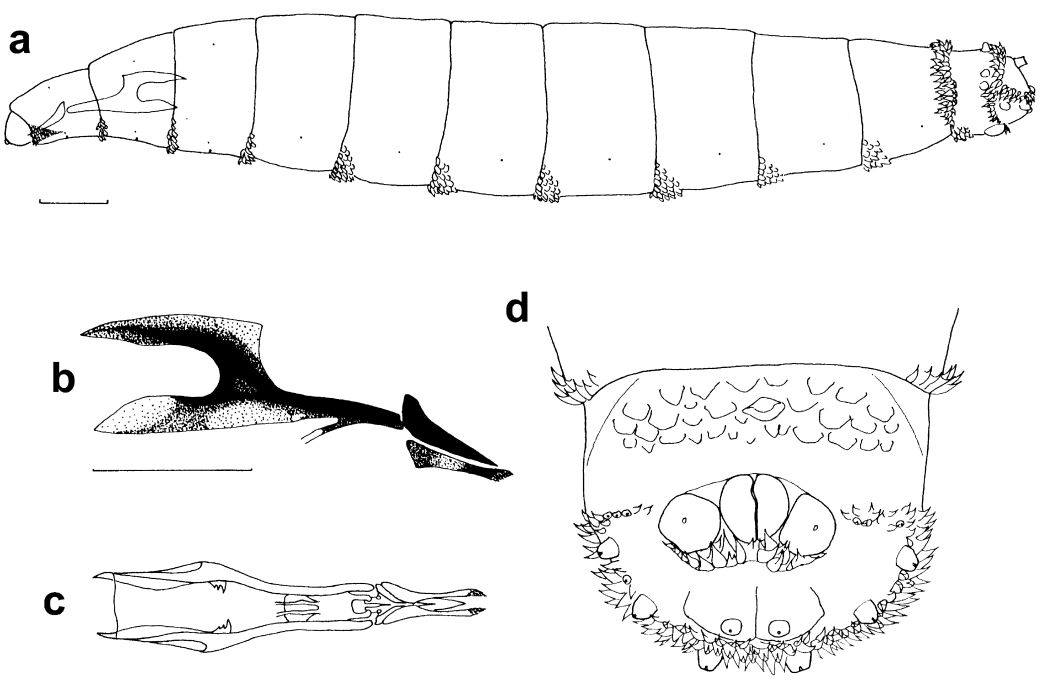

Fig. 7. First instar larva of Pollenia labialis RobineauDesvoidy, 1863. - a. Whole body. - b. Cephalopharyngeal skeleton (lateral view). c. Cephalopharyngeal skeleton (ventral view). d. Posterior body end (ventral view). Scale $0.1 \mathrm{~mm}$.
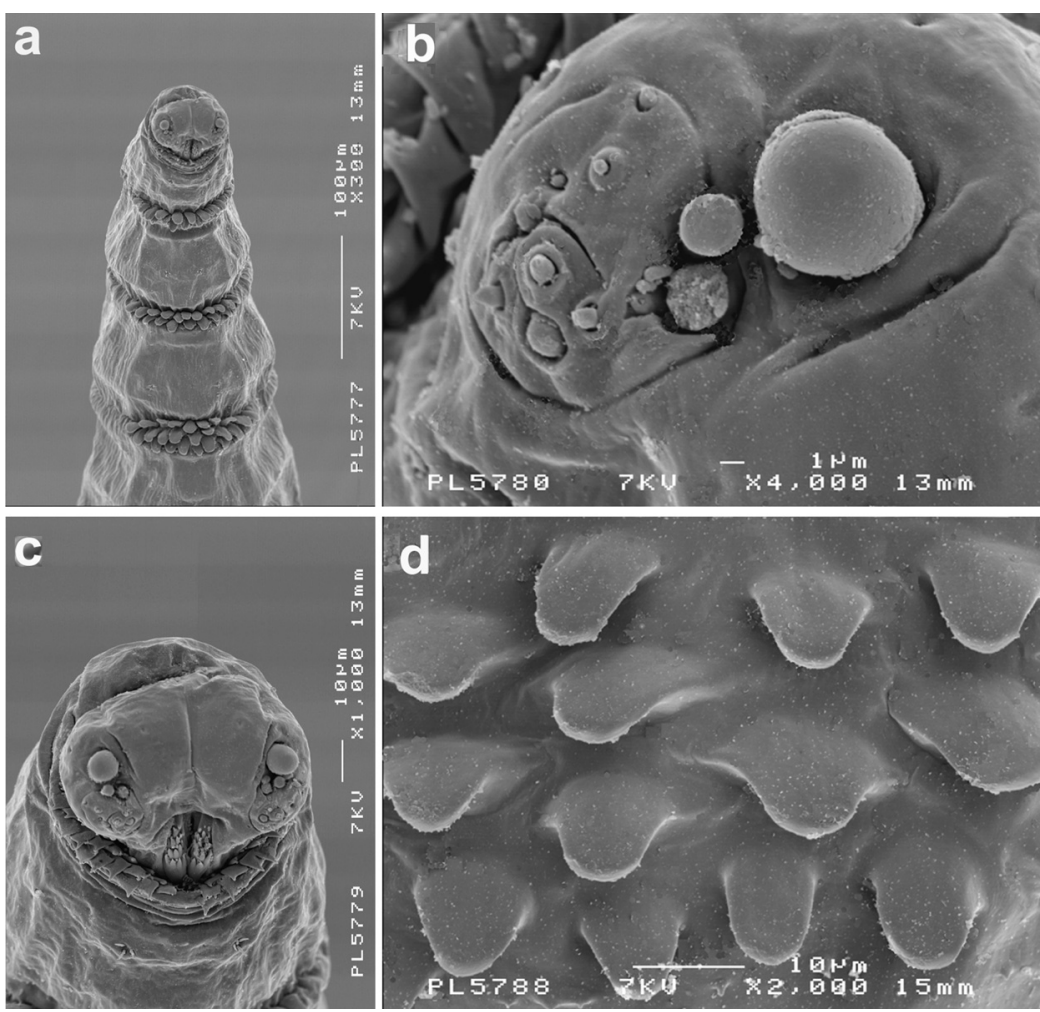

Fig. 8. First instar larva of Pollenia labialis RobineauDesvoidy, 1863. - a. Pseudocephalon and thoracic segments (ventral view). - b. Sensory organs on pseudocephalon. - c. Anterior body end (ventral view). - d. Ventral tubercles (A II).

sclerotised ventral tubercles on T II and T III. Ventral tubercles on the abdominal segments tend to be shorter and wider. No spine bands or tubercles on the anterior part of the dorsal surface of thoracic and abdominal segments. No spines dorsally along posterior edge of A VI, whereas A
VII and A VIII have spines that are stronger and larger than in the other species. No spines ventrally along the posterior edge of A VII. Strong ventral tubercles present on the ventral surface of A VIII and densely set in 3 rows. Anus oval, almost circular, with large anal papillae. 


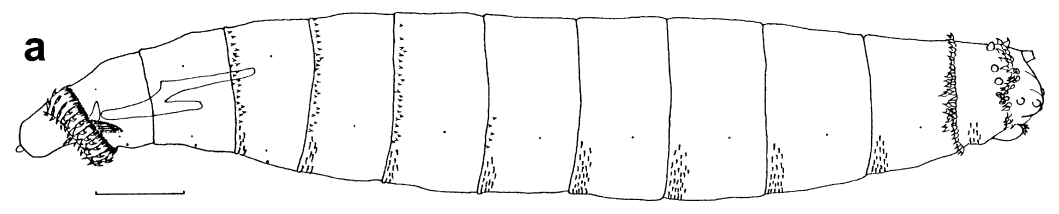

Fig. 9. First instar larva of Pollenia mayeri Jacentkovský, 1941. - a. Whole body. - b. Cephalopharyngeal skeleton (lateral view). - c. Labrum (lateral view). d. Cephalopharyngeal skeleton (ventral view). e. Posterior body end (ventral view). Scale $0.1 \mathrm{~mm}$.

b
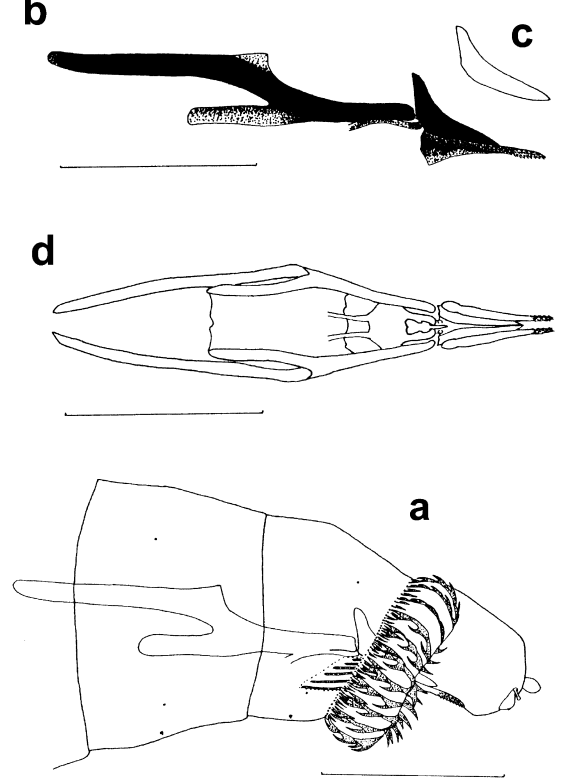

C

Fig. 10. First instar larva of Pollenia mayeri Jacentkovský, 1941, anterior body end. - a. Normal position (lateral view). - b. With fully protruded edge of $\mathrm{T}$ I (lateral view). - c. Dorsal view. - d. Ventral view. Scale $0.1 \mathrm{~mm}$.

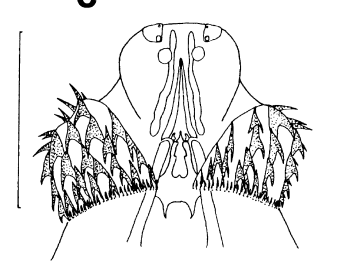

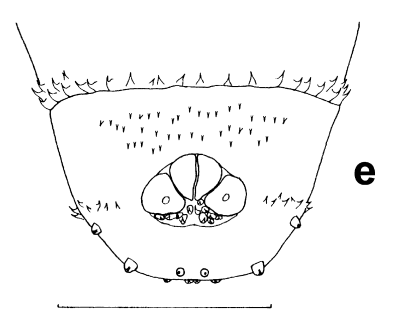

b

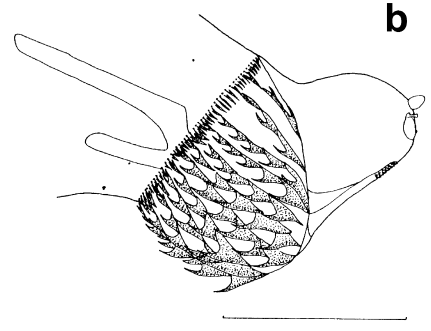

d

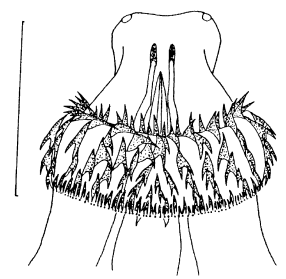

3.5. Pollenia mayeri Jacentkovský, 1941 (Figs. 9a-e, 10a-d, 11a-f)

Average body length $1.16 \mathrm{~mm}(\mathrm{SD}=0.02)$, average width $0.14 \mathrm{~mm}(\mathrm{SD}=0.004)$. Antennae oval and slightly elongated. Cephalopharyngeal skeleton highly distinctive. The labrum is straight, with the saggital cleft reaching to its tip. Mouthhooks strong and highly sclerotised, considerably longer than the labrum and with numerous spinules in the distal part. The vertical plate is at an angle of about $40^{\circ}$ towards the ventral cornua. The dorsal cornua is twice as long as the ventral. Anterior edge of $\mathrm{T}$ I armed with characteristic rows of strong hook-like spines, constituting an almost complete band which is narrowly discontinous dorsally. The rows of spines run parallel to each other and to the lengitudinal axis of the body (Fig. 10). The ventral tubercles of the thoracic and abdominal segments characteristic of the other described species are replaced by rows of sparsely distributed spinules. Dorsally and laterally along the anterior edge of T III, A I and A II, a single irregular band of larger spines that point backwards with similar spines present laterally but not dorsally along the anterior edge of A III. There are no spines dorsally along the posterior edge of A VI. One row of spines ventrally along posterior edge of A VII. The anus is oval and almost circular. 

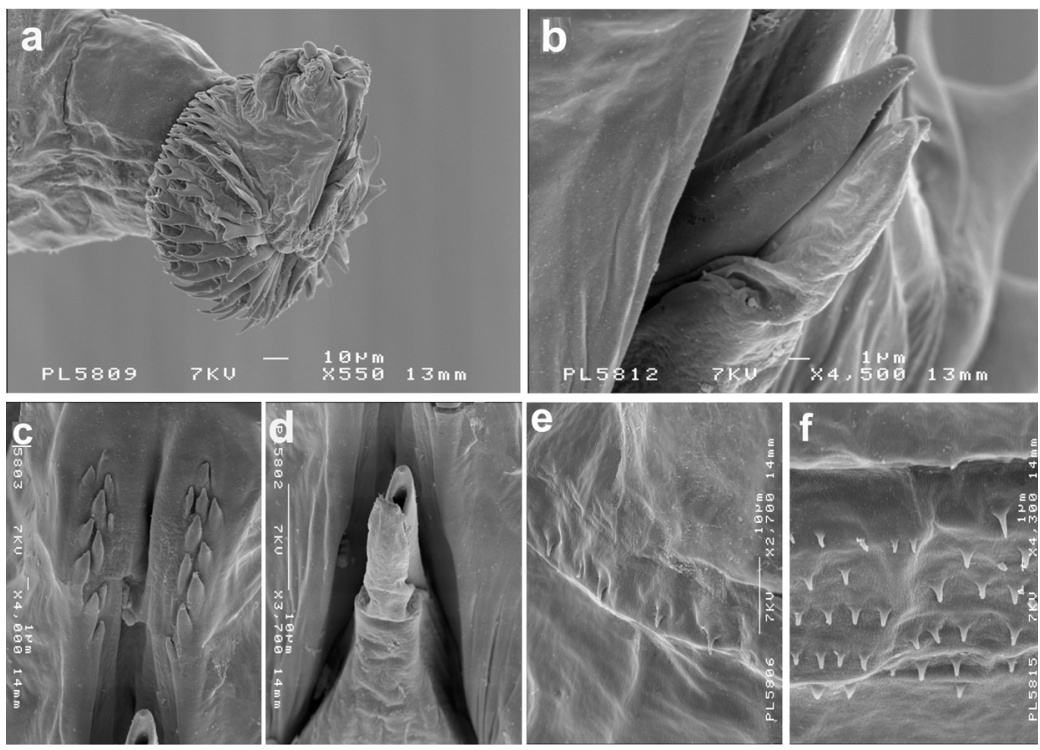

Fig. 11. First instar larva of Pollenia mayeri Jacentkovský, 1941. - a. Anterior body end. - b. Tip of labrum (lateral view). c. Spines on tip of mouthhooks. $-\mathrm{d}$. Tip of labrum (frontal view). - e. Spinulation on anterior dorsal surface of the A I. - f. Spinulation on anterior ventral surface of A II.
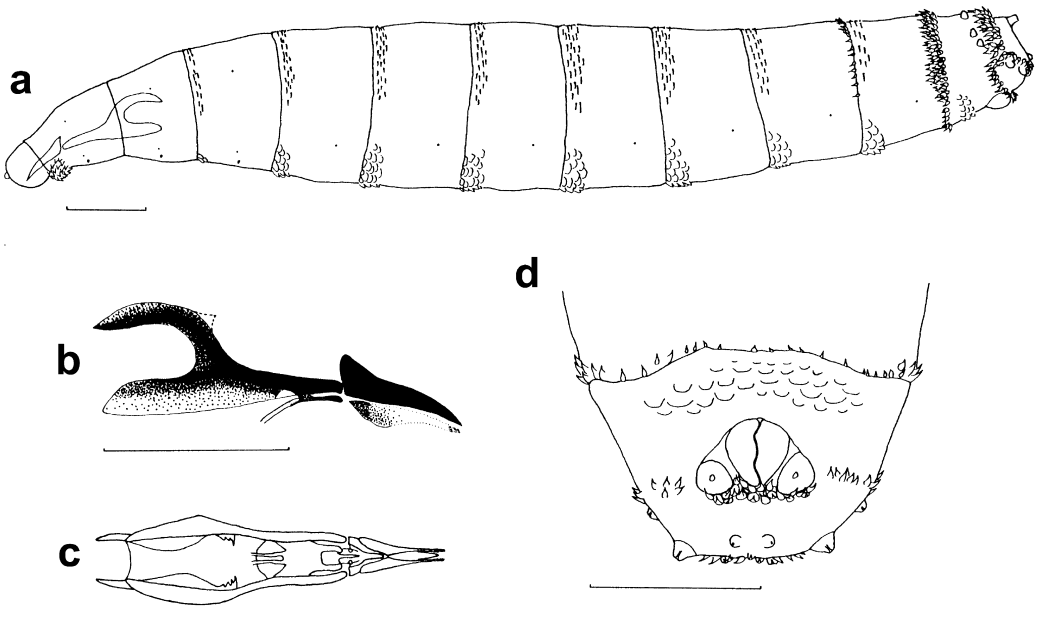

Fig. 12. First instar larva of Pollenia pediculata Macquart, 1834. - a. Whole body. - b. Cephalopharyngeal skeleton (lateral view). c. Cephalopharyngeal skeleton (ventral view). d. Posterior body end (ventral view). Scale $0.1 \mathrm{~mm}$.

3.6. Pollenia pediculata Macquart, 1834 (Figs. 12a-d, 13a-f)

Average body length $1.31 \mathrm{~mm}(\mathrm{SD}=0.04)$, average width $0.2 \mathrm{~mm}(\mathrm{SD}=0.01)$. Short, slightly flattened antennae. Labrum narrow, elongated, slightly curved downwards. Mouthhooks long, narrow, slightly turned downwards, strongly sclerotised only in the basal part. The vertical plate of average length, relatively narrow, almost as wide as the dorsal cornua. Broad, plate-like ventral tubercles present on T III and on all the abdominal segments. Several separate rows of clustered blunt- tipped spinules present anteriorly on the dorsal surface of TIII-A VII. Spines are present dorsally along posterior edge of A VI. One row of weak spines present ventrally along posterior edge of A VII. The ventral tubercles on A VIII are arranged in 3-4 rows. Anal opening oval, slightly elongated towards the length axis of the body.

\subsection{Pollenia rudis (Fabricius, 1794) (Figs. 14a-d)}

Average body length $1.56 \mathrm{~mm}(\mathrm{SD}=0.04)$, average width $0.22 \mathrm{~mm}(\mathrm{SD}=0.01)$. Antennae nearly 

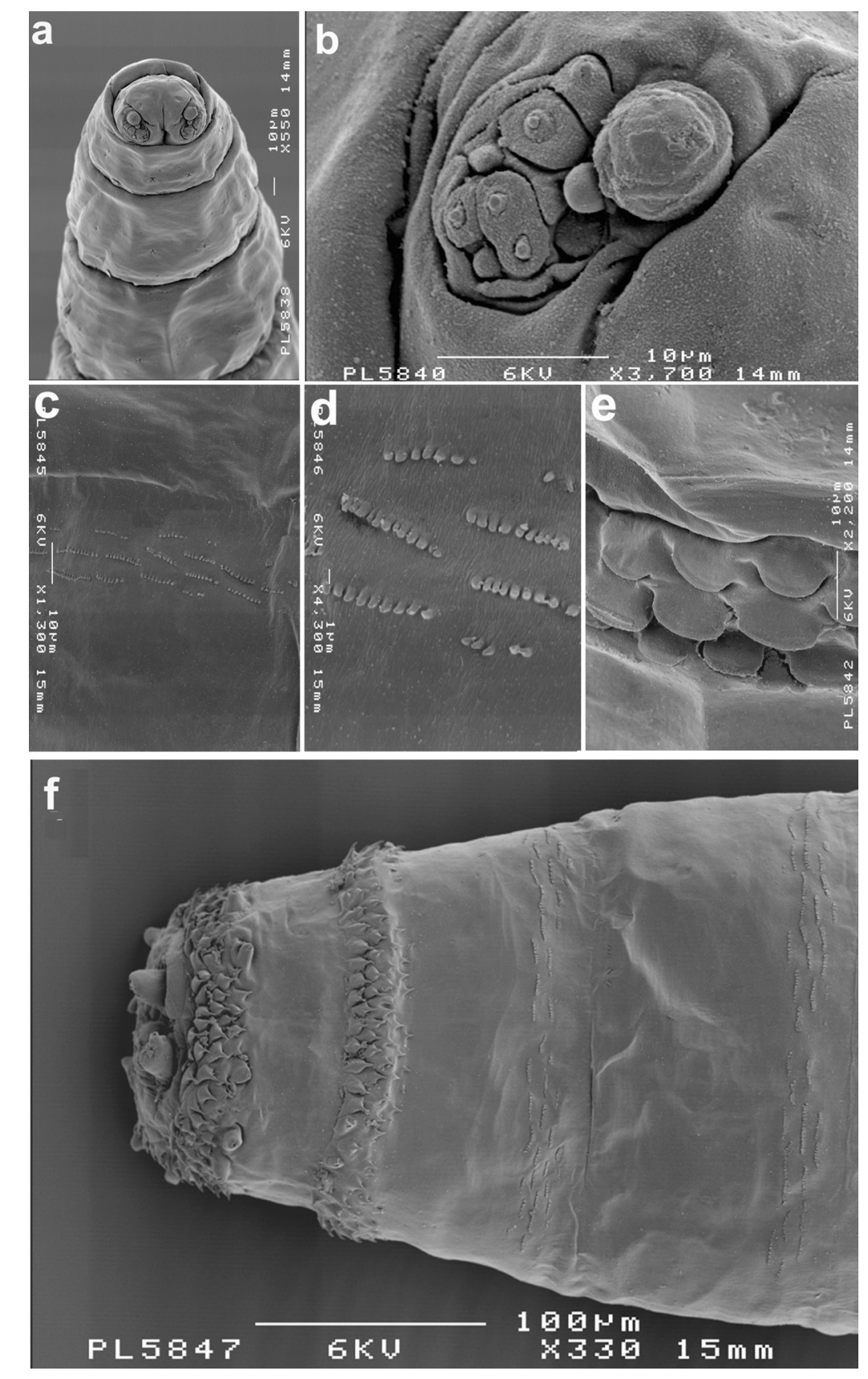

Fig. 13. First instar larva of Pollenia pediculata Macquart, 1834. - a. Anterior body end (ventral view). - b. Sensory organs on pseudocephalon. - c. Spinulation on anterior dorsal surface of the abdominal segments (A II). - d. Same. - e. Ventral tubercles (A II). - f. Posterior body end (dorsal view).

spherical. Compared to $P$. angustigena and $P$. pediculata labrum not very narrow and not elongated, slightly curved downwards. Mouthhooks of similar shape, strongly sclerotised only in the basal part. The vertical plate of average length, relatively narrow, almost as wide as dorsal cornua. Broad, plate-like ventral tubercles (as in $P$. pediculata, Fig. 13e) present on T II, T III and on all the abdominal segments. Several separate rows of clustered blunt-tipped spinules present anteriorly on the dorsal surface of TIII-A VII. There are no spines dorsally along posterior edge of A VI. One distinct row of spines along the posterior edge of the ventral part of A VII. The 


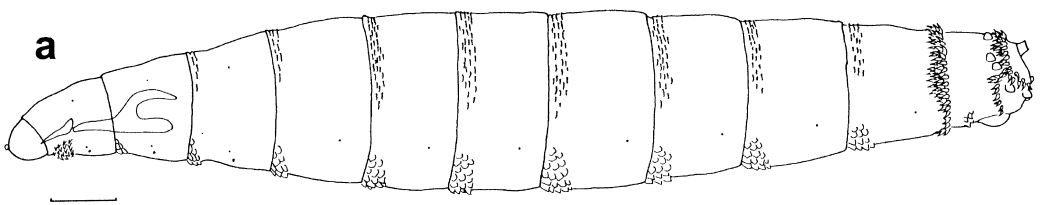

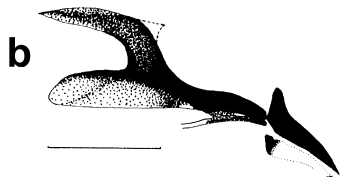

C

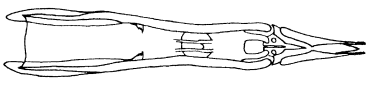

d

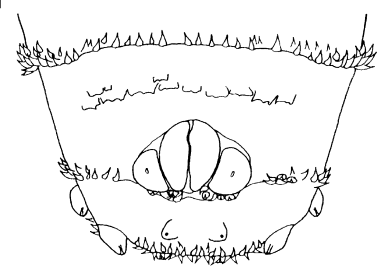

Fig. 14. First instar larva of Pollenia rudis (Fabricius, 1794). - a. Whole body. - b. Cephalopharyngeal skeleton (lateral view). c. Cephalopharyngeal skeleton (ventral view). d. Posterior body end (ventral view). Scale $0.1 \mathrm{~mm}$.

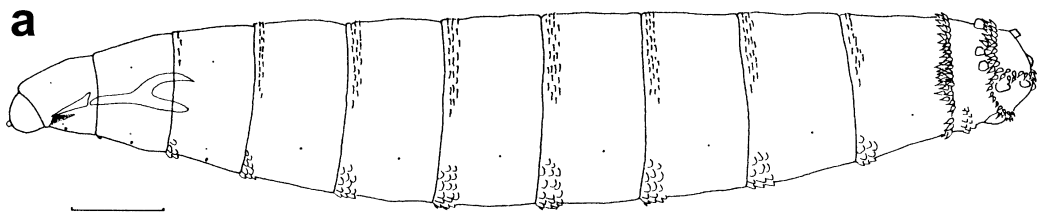

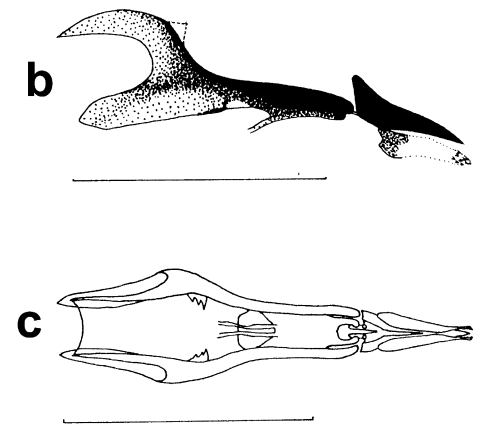

d

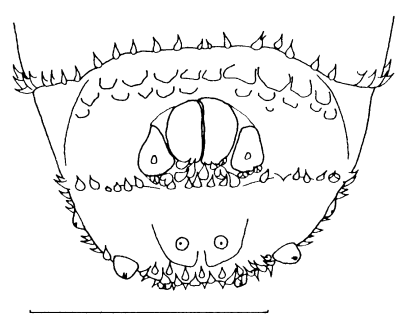

Fig. 15. First instar larva of Pollenia similis (Jacentkovský, 1941). - a. Whole body. - b. Cephalopharyngeal skeleton (lateral view). c. Cephalopharyngeal skeleton (ventral view). d. Posterior body end (ventral view). Scale $0.1 \mathrm{~mm}$. midventral tubercles on A VIII in a single row, whereas in two rows on laterally. Anal opening oval, slightly elongated towards the length axis of the body.

3.8. Pollenia similis (Jacentkovský, 1941) (Figs. 15a-d, 16a-e)

Average body length $1.13 \mathrm{~mm}(\mathrm{SD}=0.03)$, average width of $0.14 \mathrm{~mm}(\mathrm{SD}=0.004)$. Antennae slightly oblong. Labrum elongated and slightly curved downwards. Mouthhooks wide only strongly sclerotised only basally. Vertical plate of average length, relatively narrow, almost as wide as the dorsal cornua. Broad platelike ventral tubercles present on T III (sometimes also on T II) and on all abdominal segments. Several separate rows of clustered blunttipped spinules present anteriorly on the dorsal surface of segments T III-A VII. No spines occur dorsally along the posterior edge of A VI. A single row of spines ventrally along posterior edge of A VII.Ventral tubercles on A VIII in 2 rows. Anal opening rounded, anal papillae relatively small. 
Fig. 16. First instar larva of Pollenia similis (Jacentkovský, 1941). - a. Anterior body end (ventral view). - b. Spinulation on anterior dorsal surface of the abdominal segments organs on pseudocephalon. - d. Same. e. Ventral tubercles (A II).

Fig. 17. First instar larva of Pollenia vagabunda (Meigen, 1826). - a. Whole body. - b. Cephalopharyngeal skeleton (lateral view). c. Cephalopharyngeal skeleton (ventral view). d. Posterior body end (ventral view). Scale $0.1 \mathrm{~mm}$. (A II). - C. Sensory
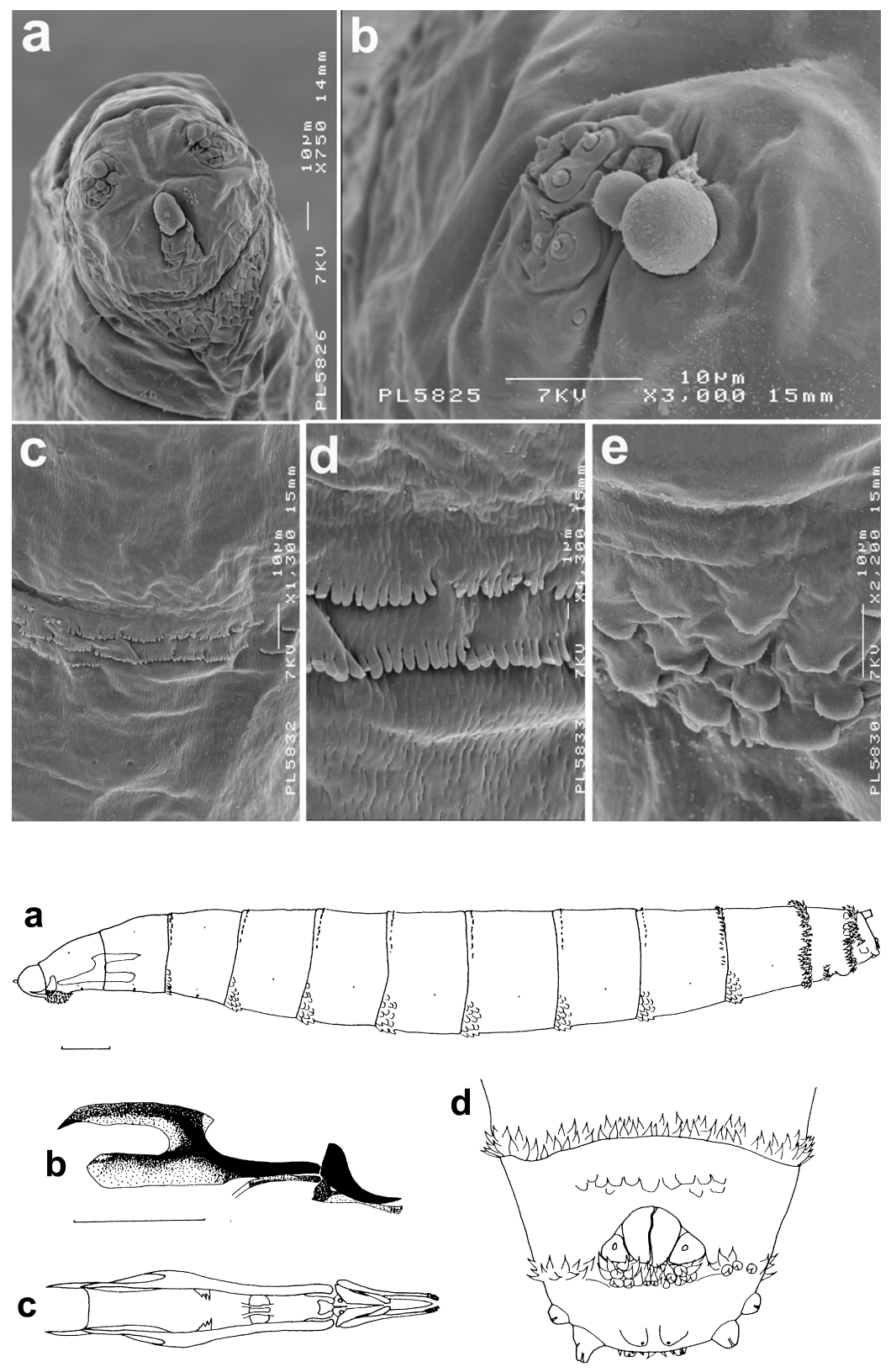

3.9. Pollenia vagabunda (Meigen, 1826) (Figs. 17a-d, 18a-e)

Average body length $1.84 \mathrm{~mm}(\mathrm{SD}=0.02)$, average width $0.22 \mathrm{~mm}(\mathrm{SD}=0.01)$. Antennae oval and elongated. Labrum curved upwards. Mouthhooks simple, strongly sclerotised at the base and narrowed in the middle part. Vertical plate short and perpendicular to the dorsal and ventral cornua. Its thinnest part is wider than the dorsal cornua at its widest. The spines along anterior edge of $\mathrm{T} \mathrm{I}$ are more numerous and more densely set than in the other species. Rather elongated, plate-like ventral tubercles occur only on 

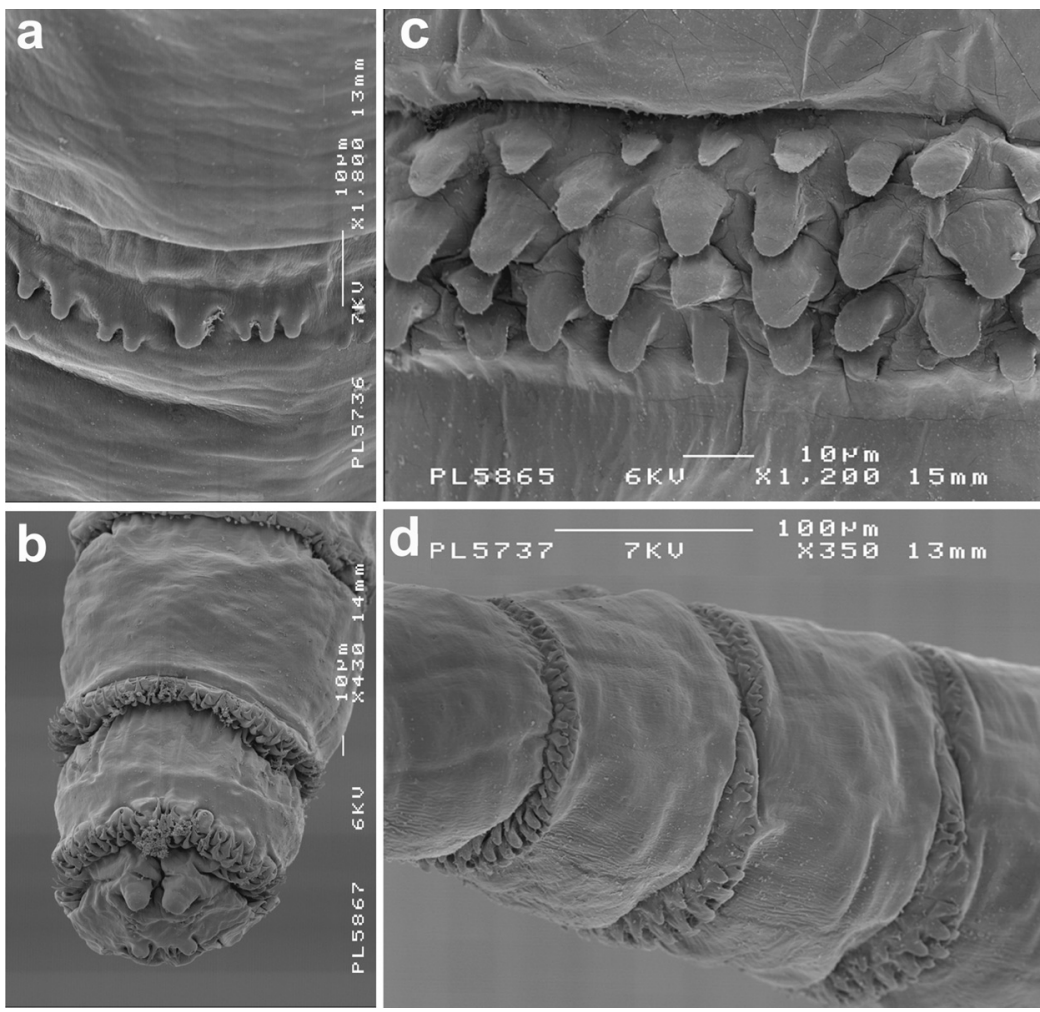

Fig. 18. First instar larva of Pollenia vagabunda (Meigen, 1826). - a. Spinulation on anterior dorsal surface of the abdominal segments (A II). - b. Posterior body end (dorsal view). - c. Ventral tubercles (A II). d. T III and Al (lateral view).

T III and on all the abdominal segments. A single discontinuous row of blunt-tipped spinules is present anteriorly on the dorsal surface of these segments. Spines present dorsally along posterior edge of A VI. Strong spines placed densely in two conspicuous rows are present ventrally along posterior edge of A VII. Ventral tubercles of A VIII in a single row, sometimes with additional papillae laterally. The anus is oval and slightly elongated.

\section{Discussion}

\subsection{Morphology of the first instar larvae}

The present work brings the number of species for which the morphology of the first instar larva is known from 2 to 11 . How useful is this knowledge for species identification? Erzinçlioğlu (1985), while studying blowfly larvae of Calliphora Robineau-Desviody, 1830 and Cynomya Robineau-Desvoidy, 1830 listed several taxonomically important features of first instar larvae: the shape and the position of spines on particular segments, the shape of the mouthhooks, the shape of the labrum, the relation between the length of the labrum and the width of the lateral plate (the vertical plate), the thickness of the hypostomal sclerite (intermediate sclerite).

However, Erzinçlioğlu (1985) questioned the usefulness of the shape and the distribution of sensory organs on the pseudocephalon. He also questioned the taxonomic usefulness of the posterior spiracles of the third instar larvae. The distribution and the shape of the papillae on abdominal segment VIII were indicated as a valuable feature, yet distinctly developed in the third instar only.

The present analysis of the first instar larvae of Pollenia leads to similar conclusions. The best taxonomic characters appear to be: the cephalopharyngeal skeleton (the shape of the labrum and the mouthhooks, the relation between the width of the vertical plate and the width of the dorsal cornua, the angle between the vertical plate and the skeleton basis), and the distribution of spines and ventral tubercles on particular segments. On the other hand, the distribution and 
shape of the sensory organs on the pseudocephalon, the level of sclerotisation of the intermediate sclerite, the vertical plate, the dorsal and ventral cornua, the size and the shape of papillae on the VIII abdominal segment, and the shape of the anal opening are of little value. These structures are prone to deformation during slide preparation, and their appearance may depend on the preparation method used.

In each species of Pollenia the larva shows one or more unique features (or a unique combination of features), confirming that each of the mentioned taxa is a valid species. The present study supports the monophyly of the rudis group. The species of the rudis group share the following features:

- downward-turned labrum and parastomal bar as long as labrum,

- wide ventral tubercles,

- single rows of blunt-tipped spinules anteriorly on the dorsal surface of the segments, and

- the presence of a single row of spines at the posterior ventral edge of A VII.

Unfortunately, the basis of present knowledge is difficult to make a firm interpretation whether the above-mentioned features are apo- or plesiomorphies. But for the present purposes I assume they are apomorphies.

There are significant morphological differences between the larvae of $P$. amentaria and $P$. atramentaria (see key). Moreover, three features of the first instar larva of $P$. atramentaria are unique and unknown in all the other Pollenia larvae known so far. These are:

- shape of antenna (considerably elongated)

- multiple rows of clustered sharp-tipped spinules on the anterior margin of the dorsal segment surface from T III to AVII, and

- rows of spines between the dorsal papillae (P1) and the dorsal and subdorsal papillae (P2).

To establish the systematic position of this species we have to know the larvae of the remaining species of the amentaria group - Pollenia vera Jacentkovský, 1936, Pollenia moravica (Jacentkovský, 1941), and Pollenia leclercqiana Lehrer, 1978.

The work by Tawfik and El-Husseini (1971) is the only source of information about $P$. dasypoda and it contains a precise description of the first instar larva, although the illustrations are very schematic and leave out some important details. The most striking differences between $P$. dasypoda and $P$. similis are the distribution and the shape of the spines and ventral tubercles on the abdominal segments. Tawfik and El-Husseini state that "each of the first seventh [sic] abdominal segments bears ventrally 2 series of spinules: one at the anterior margin and the other on the posterior one. Thus, each intersegmental groove is bordered by the 2 series of spinules, each arranged in 2 rows and with points directed backwards". In the case of $P$. similis, the anterior ventral segment surface bears ventral tubercles in the form of wide plates distributed in 3-4 rows. The authors do not mention any such structures at the anterior dorsal part of A I-VI abdominal segments in $P$. dasypoda. $P$. similis, on the other hand, shows scattered rows of spinules (similarly to the rudis group). The shape of the mouthhook also differs. In $P$. dasypoda mouthhooks are united in the basal part, they are arch-shaped with a distinct narrowing in the central part, whereas in $P$. similis they form wide, separated straight plates. A significant similarity between both larvae is found in the structure of the cephalopharyngeal skeleton. The labra are of comparable shape, slightly turned downwards. They are definitely shorter than the parastomal sclerite. Some inaccuracies in the illustrations of Tawfik and El-Husseini (1971) make it difficult to evaluate the similarities and differences between $P$. dasypoda and $P$. similis larvae in more detail.

\subsection{Key for the identification of first instar larvae}

The following key is undoubtedly incomplete. It covers larvae of only 11 of the 20 Central European species. However, the missing species are apparently uncommon, like $P$. hungarica Rognes and $P$. vera Jacentkovský, or very rare, like $P$. bulgarica Jacentkovský, $P$. pectinata Grunin, $P$. ponti Rognes, $P$. tenuiforceps Séguy, $P$. venturii Zumpt, and $P$. viatica Robineau-Desvoidy. An exception is $P$. griseotomentosa Jacentkovský, which is locally common in Central Europe. This species belongs with $P$. mayeri to the 
griseotomentosa species-group. Apart from this species, the key includes the majority of the common Pollenia species in Europe (and all the known Nearctic species). Features of $P$. dasypoda are taken from Tawfik and El-Husseini (1971).

1. Anterior edge of the T I armed with strong hook-like spines on almost the entire surface (Figs. 10a-d, 11a); the vertical plate set at an angle of about $40^{\circ}$ in relation to the ventral cornu; the dorsal cornu more than twice as long as the ventral cornu (Fig. 9b); no ventral tubercles on A VIII .............. P. mayeri Jacentkovský

- Anterior edge of T I armed with spines only on the ventral and partly on the lateral surfaces (Fig. 1a); the vertical plate is situated at an angle of more than $50^{\circ}$ towards the ventral cornua; the dorsal cornua of the same length or slightly longer than the ventral cornua (Fig. 1b)

2. Labrum clearly turned upwards (Figs. 5b, 17b) ..... 3

- Labrum straight or turned downwards (Figs. 1b, 2b, 7b)

3. Labrum strongly turned upwards; vertical plate short, wider than the widest part of the dorsal cornua (Fig. 17b); no ventral tubercles on T II; a single discontinuous row of blunt-tipped spinules in the anterior dorsal part of each segment (Fig. 18a); no rows of spines present between the dorsal papillae (P1) and the dorsal and subdorsal papillae (P2) (Fig. 18b) ....

P. vagabunda (Meigen)

- Labrum slightly turned upwards; vertical plate long with its thinnest part finer than the widest part of the dorsal cornua (Fig. 5b); numerous ventral tubercles on T II; irregular rows of clustered sharp-tipped spinules present on the antero-dorsal segment surface (Fig. 6c); rows of spines between the dorsal papillae (P1) and the dorsal and subdorsal papillae (P2) (Fig. 6e) .

P. atramentaria (Meigen)

4. Labrum straight (Figs. 2b, 7b) ................................. 5

- Labrum turned downwards (Fig. 1b) ......................... 6

5. Labrum is relatively short; mouthhooks highly sclerotised and widening in the distal part; vertical plate wide (Fig. 7b); numerous long and slightly sclerotised ventral tubercles on T II and T III (Fig. 8a); no spine rows or tubercles anteriorly on the dorsal surface the thoracic and abdominal segments; no spines ventrally along the posterior edge of A VII (Fig. 7d)

P. labialis Robineau-Desvoidy

- Labrum narrow and considerably elongated; mouthhooks poorly sclerotised only in the proximal part and not widening in the distal part; narrow vertical plate (Fig. 2b); ventral tubercles on T II and T III relatively wide and not sclerotised; $2-3$ rows of clustered blunttipped spinules present anteriorly on the dorsal surface of each segment (Fig. 3e); strong spines in two distinct rows ventrally along the posterior edge of A VII (Fig. 2d) …............................... P. amentaria (Scopoli)

6. Parastomal bar as long as labrum, or shorter (Fig. 1b)
- Parastomal bar apparently longer than labrum (Fig. 15b)

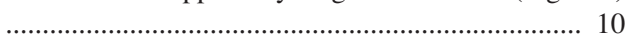

7. Upper angle of the basal part of the labrum not protruding (Fig. 1g); hook-like spines present at the anterior and posterior margins of the abdominal segments (Fig. 1h)

... Pollenia sp. [= the larva described by Keilin (1915)]

- Upper angle of the basal part of the labrum protruding (Fig. 1b); ventral tubercles present only at the anterior margins of the abdominal segments ........................ 8

8. Labrum slowly narrowing from its broadened base, the angle between the edges forming the top of the labrum wider than $40^{\circ}$ (Figs. 1f, 12b); ventral tubercles on A VIII in 3-4 rows (Fig. 12d).. P. pediculata Macquart

- Labrum sharply narrowing from its broadened base, the angle between the edges forming the top of the labrum not wider than $35^{\circ}$ (Figs. 1e, 4b, 14b); ventral tubercles on A VIII in the middle part in one row, and $2-3$ rows at the sides (Figs. 4d, 14d)

\section{9}

9. A VI in the postero-dorsal part with a single row of lobelike spines without sharp points (Fig. 4a); labrum long and slender (Fig. 4b) ....... P. angustigena Wainwright

- A VI devoid of spines in the postero-dorsal part (Fig. 14a); labrum relatively short and robust (Fig. 14b) .... ....................................... P. rudis (Fabricius)

10. Mouthhooks short and wide (Fig. 15b); ventral tubercles present only at the anterior margins of the abdominal segments (Fig. 15a) ............ P. similis (Jacentkovský)

- Mouthhooks not particularly short and wide; ventral tubercles at the anterior and posterior margins of the abdominal segments.......... P. dasypoda Portschinsky

\subsection{Illustrations in other publications}

Original illustrations of the first instar Pollenia larvae are included in the works of Keilin (1915), Tawfik and El-Husseini (1971), Yahnke and George (1972), Richards and Morrison (1973), and Shewell (1987). The work by Tawfik and ElHusseini concerns $P$. dasypoda, whereas the remaining publications mentioned above described the " $P$. rudis" larvae.

Yahnke and George (1972) described the larval stages and the biology of some species and compared their results with those of Keilin (1909). They concluded that the larvae presented in both publications must belong to different subspecies or even different species. On the basis of the structure of the puparium, Rognes (1987) excluded the species described by Keilin from the rudis group. Next, analysing the phenology and imaginal behaviour of various Pollenia species, he proposed the tentative hypothesis that the species described 
by Keilin belongs to the viatica species-group (Rognes 1991, 1998). The results obtained in the present work (see above) confirm the doubts concerning the identity of Keilin's species.

Rognes $(1991,1998)$ identified 81 imagines reared by Yahnke and George. P. pediculata dominated $(92.6 \%, 75$ specimens) over $P$. rudis (6 specimens). On that basis Rognes concluded that the illustrations presented by Yahnke and George (1972) probably regarded $P$. pediculata. A comparison of their illustrations with the description of the first instar larva in the present work confirms this conclusion. It is based on a set of morphological features:

- the angle between the edges forming the top of the broadened basal part of the labrum is above $40^{\circ}$,

- no ventral tubercles on the T II,

— spines present dorsally along posterior edge of A VI, and

- the average length of a newly hatched larva of about $1.3 \mathrm{~mm}$.

The length of the larva seems to be the least reliable feature because the soft body cover is prone to damage. Yet the sizes of the freshly hatched $P$. angustigena and $P$. rudis larvae are clearly larger and in the case of both species reach $1.56-1.58 \mathrm{~mm}$.

The illustrations presented in Shewell (1987) seem to be more difficult to interpret as they show fewer details - the only part illustrated is the anterior part of larva classified as Pollenia sp. (seen laterally and ventrally). The larva illustrated stem from Yahnke and George (K. Rognes pers. comm.). Unfortunately, the publication does not give any description of other parts of the larva, but it undoubtedly belongs to the rudis group. It differs from the larvae of $P$. labialis and $P$. vagabunda, the other known Nearctic species (Rognes 1991b, 1998), in the structure of the cephalopharyngeal skeleton and in the lack of the characteristic ventral tubercles on the anterior edge of the T II and T III (P. labialis). Tentatively, the species may be identified as $P$. pediculata. Unfortunately the original slide was lost (J. Cumming, pers. comm.).

The publication of Richards and Morrison (1973) contains only one illustration of a first instar larva, a dorsal view of the last two abdominal seg- ments. Unfortunately, due to the omission of many morphological details, the illustration allows no identification to species. However, the reported size of the first instar larvae -1.12 to $1.50 \mathrm{~mm}$ in length (1.34 on average) - points to $P$. pediculata.

\section{Conclusions}

The morphology of the first instar larvae of Pollenia known so far makes it possible to identify them with the use of suitable preparation methods (see Material and Methods). The features most useful for species identification are

- the shape of the labrum,

- the shape of the mouthhooks,

- the shape and the position of the vertical plate in relation to the remaining elements of the cephalopharyngeal skeleton,

- the shape and the distribution of the ventral tubercles and analogous structures in the dorsal part of the larval segments, and

- the spinulation on the terminal abdominal segments (A VI-A VIII).

The analysis of original illustrations and descriptions of the first instar larvae of Pollenia rudis in the works published prior to the species revision by $\mathrm{K}$. Rognes is hampered by their rather insufficient quality and the lack of precision except for the work by Yahnke and George. The species they described must be $P$. pediculata. The illustrations of the larva from the work by Shewell (1981) concern probably the same species, the larva described by Keilin remains unidentified.

Acknowledgements. The present work was possible due both to a State Committee for Scientific Research grant (nr. 6PO4C 014 17) and HIGH LAT programme of the Swedish Museum of Natural History. I would like to thank Prof. A. Draber-Mońko for inspiration and help. I also thank Prof. $\mathrm{K}$. Rognes and Dr T. Pape for advice and information and for critical reading of the manuscript.

\section{References}

Courtney, G. W., Sinclair B. J. \& Meier, R. 2000: Morphology and terminology of Diptera larvae. In: Papp, L. \& Darvas, B. (eds.), Manual of Palaearctic Diptera 1: 85-162. Science Herald, Budapest. 994 pp. 
Decoursey, R. M. 1927: A bionomical study of the cluster fly Pollenia rudis (Fab.) (Diptera, Calliphoridae). Ann. Ent. Soc. Am. 20: 236-281.

Decoursey, R. M. 1932: The feeding habits of the first instar larvae of the cluster fly. - Science 75: 287.

Erzinçlioğlu, Y. Z. 1985: Immature stages of British Calliphora and Cynomya, with re-evaluation of the taxonomic characters of larval Calliphoridae (Diptera). J. Nat. Hist. 19: 69-96.

Hall, D. G. 1948: The blowflies of North America. - Thomas Say Foundation, Lafayette, Indiana. $6+477$ pp.

Ibrahim, S. H. 1984: A study on a dipterous parasite of honeybees. - Z. Ang. Ent. 97: 124-126.

Keilin, D. 1909: Sur le parasitisme de la larvae de Pollenia rudis FAB. dans Allolobophora chlorotica Savigny. Compt. Rend. Soc. Biol. Paris 67: 201-203.

Keilin, D. 1915: Recherches sur les larves de Dipteres cyclorhapes. Cycle evolutif de Pollenia rudis Fabr., parasite d'Allolobophora chlorotica Sav. - Biologie comparee des larves de Dipteres. - Bull. Sci. Fr. Belg. 49: 15-198.

Krivosheina, N. P. 1961: Diptera larvae feeding on earthworms. — Zool. Zh. 40: 715-718. [In Russian].

Pimentel, D. \& Epstein, B. 1960: The cluster fly Pollenia rudis (Diptera: Calliphoridae). — Ann. Ent. Soc. Am. 53: 553-554.

Richards, P. G. \& Morrison, F. O. 1973: Pollenia rudis (Diptera: Calliphoridae) reared on Allolobophora chlorotica (Annelida: Lumbricidae). — Phytoprotection 54: $1-8$.

Rognes, K. 1987: The taxonomy of the Pollenia rudis species group in the Holarctic Region (Diptera: Calliphoridae). - Syst. Ent. 12: 475-502.

Rognes, K. 1988: The taxonomy and phylogenetic relationships of the Pollenia semicinerea species group (Diptera: Calliphoridae). — Syst. Ent. 13: 315-345.

Rognes, K. 1991a: Revision of the cluster-flies of the Pollenia viatica species-group (Diptera: Calliphoridae). — Syst. Ent. 16: 439-498.

Rognes, K. 1991b: Blowflies (Diptera, Calliphoridae) of Fennoscandia and Denmark. — Fauna Ent. Scand. 272 pp.

Rognes, K. 1991c: Revision of the species of Pollenia Robineau-Desvoidy described by Camillo Rondani (Diptera: Calliphoridae). — Ent. Scand. 22: 365-367.
Rognes, K. 1992: Revision of the cluster-fly of the Pollenia vagabunda species-group (Diptera: Calliphoridae). Ent. Scand. 23: 95-114.

Rognes, K. 1998: 3.51. Family Calliphoridae. — In: Papp, L. \& Darvas, B. (eds.), Manual of Palaearctic Diptera, 3: 617-648. Science Herald, Budapest. 880 pp.

Seguy, E. 1941: Etudes sur les mouches parasites. Tome II. Calliphorides. - Encycl. Ent. (A) 21: 1-436.

Shewell, G. E. 1987: 106 Calliphoridae. In: McAlpine, J. F., Peterson, B. V., Shewell, G. E., Teskey, H. J., Vockeroth, J. R. \& Wood, D. M. (eds.), Manual of Nearctic Diptera 2: 1133-1145. Res. Branch Agric. Canada Monogr., Ottawa.

Tawfik, M. F. S. \& El-Husseini, M. M. 1971: Life-history of Pollenia dasypoda Portochisky [sic], a parasite of the earth worm, Allolobophora caliginosa (Sav.) (Diptera: Calliphoridae). — Bull. Soc. Ent. Egypte 55: 275-287.

Thomson, A. J. \& Davies, D. M. 1973a: The biology of Pollenia rudis, the cluster fly (Diptera: Calliphoridae). I. Host location by first instar larvae. - Can. Ent. 105: $335-341$.

Thomson, A. J. \& Davies, D. M. 1973b: The biology of Pollenia rudis, the cluster fly (Diptera: Calliphoridae). II. Larval feeding behaviour and host specificity. Can. Ent. 105: 985-990.

Thomson, A. J. \& Davies, D. M. 1974: The biology of Pollenia rudis, the cluster fly (Diptera: Calliphoridae). III. The effect of soil conditions on the host-parasite relationship. - Can. Ent. 106: 107-110.

Viktorov-Nabokow, O. V. \& Verves, J. G. 1975: K izucheniu mukh (Diptera: Calliphoridae, Sarcophagidae), parazitiruyushchikh v dozhdevykh chervyakh (Oligochaeta, Lumbricidae). — Sbor. Probl. Pochv. Zool. [1975]: 97-98. [In Russian].

Webb, J. L. \& Hutchinson, H. H. 1916: A preliminary note on the bionomics of Pollenia rudis, Fabr. in America. — Proc. Ent. Soc. Wash.18: 197-199.

Yahnke, W. \& George, J. A. 1972: Rearing and immature stages of the cluster fly (Pollenia rudis) (Diptera: Calliphoridae) in Ontario. - Can. Ent. 104: $567-$ 576.

Zrazhevskiy, A. I. 1957: Dozhdevye chervi kak faktor plodorodiya lesnykh potchv. — Izd. Akad. Nauk Ukr. SSR, Kiev. 268 pp. [In Russian]. 